\title{
Evaluasi Pelaksanaan Webinar Pusdiklat Perdagangan Dengan Menggunakan Text Mining: Analisis Saran Peserta Webinar
}

\author{
Hari Linda Lukitowati', Luksi Paryatno² \\ Pusdiklat Perdagangan Kementerian Perdagangan \\ email: Iparyatno@gmail.com
}

\begin{abstract}
Abstrak
Pusat Pendidikan dan Pelatihan Perdagangan (Pusdiklat Perdagangan) turut serta berperan dalam pengembangan kompetensi dan keterampilan masyarakat Indonesia. Salah satu bentuk kontribusi yang dilakukan yaitu menyelenggarakan webinar melalui learning management system (LMS) Kudagang. Sebagai pusat pendidikan dan pelatihan yang menyelenggarakan kegiatan webinar infografis, Pusdiklat Perdagangan berharap dapat memberikan layanan yang terbaik. Oleh karena itu, evaluasi kegiatan menjadi satu hal wajib yang harus dilakukan. Materi infografis menjadi satu topik webinar yang diberikan kepada peserta, baik dari kalangan akademisi maupun profesional. Untuk memberikan pelayanan yang optimal, Pusdiklat Perdagangan melakukan evaluasi terhadap kegiatan webinar melalui saran peserta. Tujuan penelitian ini adalah untuk mengidentifikasi hal-hal yang perlu dibenahi dan ditingkatkan dalam penyelenggaraan webinar yang akan datang agar kualitas layanan yang diberikan optimal dan mengidentifikasi topik dan materi webinar yang benar-benar dibutuhkan oleh masyarakat. Saran peserta yang berupa teks diolah dan dianalisis menggunakan text mining. Analisis data terdiri dari dua bagian: (1) analisis saran mengenai pelaksanaan webinar; (2) saran topik webinar selanjutnya. Hasil analisis terhadap saran peserta menunjukkan beberapa hal yang harus diperbaiki dalam pelaksanaan webinar, di antaranya kualitas audio, durasi praktik, cara penyampaian materi, dan peranan host dalam memandu kegiatan webinar. Saran topik webinar yang diberikan oleh peserta kepada Pusdiklat Perdagangan adalah pembuatan infografis lanjutan, pengelolaan media sosial, public speaking, komunikasi efektif, dan penuliasan artikel ilmiah.
\end{abstract}

Keywords: webinar, infografis, text mining, evaluasi, learning management system

\begin{abstract}
The Trade Education and Training Center (Pusdiklat Perdagangan) participates in the development of competencies and skills of the Indonesian people. One of contribution is organizing webinars through the learning management system (LMS) Kudagang. As an education and training center that organizes infographic webinars, Pusdiklat Perdagangan hopes to provide the best service. Therefore, evaluation is a mandatory thing that must be done. The infographic became a webinar topic that was given to participants, both academics and professionals. To provide optimal service, Pusdiklat Perdagangan evaluates webinar activities through participant suggestions. The purpose of this study is to identify things that need to be addressed and improved in the implementation of future webinars so that the quality of services provided is optimal and identify topics and webinar materials that are really needed by the community. Suggestions from participants in the form of text are processed and analyzed using text mining. The data analysis consisted of two parts: (1) analysis of suggestions regarding the webinar activities; (2) suggestions
\end{abstract}


for the next webinar topic. The results of the analysis of participant suggestions indicate several things that need to be improved in the implementation of the webinar, including the audio quality, the practice duration, the technique in delivering material, and the role of the host in guiding the webinar activities. The webinar topic suggestions given by the participants to Pusdiklat Perdagangan are advanced infographics, social media management, public speaking, effective communication, and how to write scientific articles.

Keywords: webinar, infographic, text mining, evaluation, learning management system

\section{PENDAHULUAN}

\section{Latar Belakang}

Pandemi COVID-19 telah memberikan dampak yang begitu besar terhadap berbagai aspek kehidupan masyarakat. Salah satu dampak yang dirasakan bagi masyarakat adalah perubahan pola perilaku dan bentuk kegiatan sehari-hari. Selain perubahan signifikan pada pola perilaku masyarakat yang lebih mengarah pada gaya hidup sehat, perubahan besar juga tampak pada kegiatan jual-beli, tata cara bertransaksi keuangan dan pembayaran, serta proses pendidikan, pembelajaran, dan pelatihan.

Kegiatan pendidikan, pembelajaran, dan pelatihan yang dilakukan oleh lembaga pendidikan formal, non-formal, maupun profesional dengan metode tatap muka langsung, harus berubah melalui berbagai media digital yang dilaksanakan secara online. Proses pendidikan, pembelajaran, dan pelatihan secara online dengan memanfaatkan teknologi digital telah menjadi suatu tren global (Gegenfurtner et al., 2019). Salah satu bentuk kegiatan pendidikan, pembelajaran, dan pelatihan yang menarik perhatian dan telah diterapkan oleh banyak institusi maupun organisasi adalah webinar. Webinar (web-based seminar) merupakan seminar berbasis web yang menghubungkan antara narasumber dan peserta seminar secara live menggunakan virtual platform meskipun narasumber dan peserta webinar berada pada lokasi yang berjauhan (Gegenfurtner dan Ebner, 2019).

Pusat Pendidikan dan Pelatihan (Pusdiklat) Perdagangan sebagai instansi pemerintah yang memiliki peran untuk berkontribusi terhadap pengembangan sumber daya manusia (SDM) diwajibkan turut serta beradaptasi terhadap perubahan pola perilaku masyarakat dalam menjalani proses pendidikan, pembelajaran, dan pelatihan. Bentuk adaptasi dan inovasi Pusdiklat Perdagangan untuk kebutuhan pendidikan, pembelajaran, dan pelatihan di masa pandemi COVID-19 sekaligus era digital yaitu mengembangkan platform pembelajaran dalam bentuk learning management system (LMS) yang dinamakan Kudagang.

Nama Kudagang merupakan akronim dari Kompetensi Unggul Perdagangan, sebuah elearning center Kementerian Perdagangan berbasis web yang berisikan sistem manajemen pembelajaran mulai dari proses administrasi hingga evaluasi pembelajaran. Kudagang memiliki beberapa bentuk layanan, salah satunya adalah webinar.

Di antara webinar yang telah dilaksanakan oleh Pusdiklat Perdagangan melalui Kudagang yaitu webinar infografis. Penyelenggaraan webinar infografis bertujuan untuk meningkatkan kompetensi dan keterampilan masyarakat, baik dari kalangan akademisi maupun profesional dalam pembuatan infografis. Data, pengetahuan, dan informasi yang direpresentasikan dalam bentuk visual grafis inilah yang dikenal dengan istilah infografis (Ismaeel et al., 2021). Tampilan infografis dapat berupa grafik, diagram, gambar, serta video yang disajikan dalam bentuk interaktif. Melalui infografis, data dan informasi yang kompleks dapat disampaikan dalam bentuk yang sederhana, efektif, dan efisien. Bahkan infografis dapat meningkatkan 
minat membaca dan belajar seseorang (Mansur dan Rafiudin, 2020).

Pentingnya infografis tersebut yang mendorong Pusdiklat Perdagangan untuk menyelenggarakan webinar infografis bagi masyarakat sebagai sarana peningkatan kompetensi dan keterampilan dalam menyajikan data, informasi, dan pengetahuan baik digunakan untuk tujuan edukasi, pekerjaan, maupun bisnis.

Sebagai pusat pendidikan dan pelatihan yang menyelenggarakan kegiatan webinar infografis, Pusdiklat Perdagangan berharap dapat memberikan layanan yang terbaik. Oleh karena itu, evaluasi kegiatan menjadi satu hal wajib yang harus dilakukan oleh Pudisklat Perdagangan. Evaluasi kegiatan dapat didefinisikan sebagai suatu proses pemerikasaan kegiatan dengan menggunakan standar tertentu (Rachman, 2020). Evaluasi kegiatan webinar merupakan suatu bentuk cara untuk mengukur performa kegiatan yang telah terlaksana dan mengumpulkan feedback dari peserta terkait hal-hal yang perlu untuk diperbaiki oleh Pusdiklat Perdagangan. Evaluasi kegiatan webinar juga berguna untuk mendapatkan informasi yang valid mengenai kebutuhan dan minat peserta terhadap topik webinar.

Feedback peserta dalam evaluasi webinar infografis disampaikan melalui saran sehingga pendekatan yang akan digunakan adalah text analysis. Text analysis memberikan kemudahan dalam mengekstraksi setiap kata yang muncul pada setiap saran dibandingkan cara manual yang mengharuskan membaca satu per satu saran sehingga melalui text analysis banyaknya saran yang diperoleh dapat diungkap dengan cepat dan objektif. Heryanto dan Pramudita (2020) menerapkan text analysis dalam mengolah opini media sosial terhadap produk hijab, Olive et al. (2020) menerapkan text analysis untuk mengevaluasi kinerja layanan transportasi online melalui opini masyarakat, dan Novialdy et al. (2020) menggunakan text analysis untuk melihat interaksi mahasiswa dalam kuliah online. Sipayung et al. (2020) menerapkan text analysis untuk menilai jawaban tes essay calon pegawai.
Penelitian ini menerapkan text analysis dengan menggunakan metode text mining untuk mengevaluasi pelaksanaan webinar infografis yang diselenggarakan oleh Pusdiklat Perdagangan sehingga hasil penelitian ini dapat memberikan kontribusi yang positif untuk perbaikan penyelenggaraan kegiatan webinar yang akan datang dan menyediakan topiktopik kegiatan yang sesuai dengan kebutuhan masyarakat.

\section{Rumusan Masalah}

Berdasarkan latar belakang yang telah dijelaskan, maka terdapat beberapa rumusan masalah dalam penelitian ini, yaitu:

a. Apa saja hal-hal yang menjadi bahan evaluasi untuk perbaikan dan peningkatan kualitas layanan dalam penyelenggaraan kegiatan webinar?

b. Apa saja topik dan materi webinar yang dibutuhkan oleh masyarakat?

\section{Tujuan Penelitian}

Tujuan penelitian ini yaitu:

a. Mengidentifikasi hal-hal yang perlu dibenahi dan ditingkatkan dalam penyelenggaraan webinar yang akan datang agar kualitas layanan yang diberikan optimal.

b. Mengidentifikasi topik dan materi webinar yang benar-benar dibutuhkan oleh masyarakat.

\section{METODOLOGI}

Metode penelitian yang digunakan dalam penelitian ini adalah metode kualitatif dengan menggunakan data teks berupa saran-saran yang diberikan oleh peserta webinar infografis

\section{Teknik Pengumpulan Data}

Teknik pengambilan data menggunakan kuesioner dengan pertanyaan terbuka (openended question) yang diberikan kepada 116 peserta webinar infografis. Pertanyaan terbagi atas dua kategori, yaitu saran mengenai berlangsungnya pelaksanaan webinar dan saran topik atau tema webinar mendatang. Ada pun metode analisis data yang digunakan yaitu text mining. 


\section{Text Mining}

Text mining merupakan suatu teknik yang digunakan untuk menggali informasi dan pengetahuan dari suatu teks (Kwartler, 2017). Kumar dan Bhatia (2013) mendefinisikan text mining sebagai proses mengekstrak informasi dari teks yang digunakan untuk suatu tujuan tertentu. Di antara teknik yang digunakan dalam text mining yaitu mengukur asosiasi atau hubungan, network analysis, visualisasi dan analisis prediktif.

Beberapa kelebihan text mining antara lain kecepatan analisis penggunaan teks, kata, dan interpretasi, serta kemudahan untuk memvisualisasikan hasil analisis sedangkan kekurangannya yaitu kuatnya subjektivitas dalam persepsi penilaian dalam mengukur sentimen suatu kata dalam teks.

Silge dan Robinson (2017) menggambarkan tahapan dalam text mining yang ditampilkan pada flowchart berikut.

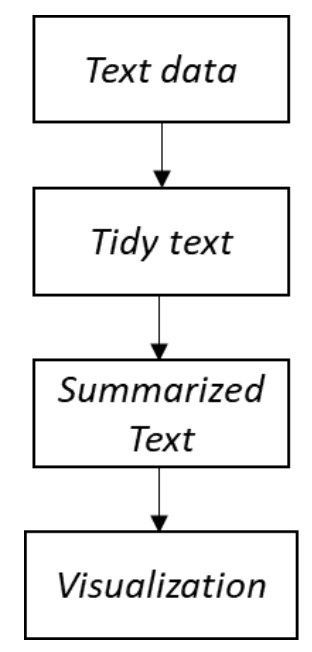

\section{Gambar 1. Flowchart text mining}

Flowchart di atas menunjukkan 4 tahapan penting dalam text mining, yaitu:

a. Menyiapkan data (text data)

Tahapan pertama adalah menyiapkan data teks yang akan digunakan untuk analisis. Teks dapat berupa naskah dan dokumen.

b. Membersihkan data (tidy text)

Membersihkan data termasuk dalam preprocessing artinya menyiapkan data sebelum menganalisis. Dua bagian penting dalam proses ini adalah tokenization dan stopwords removal. Tokenization adalah proses memisahkan kalimat menjadi kata per kata sedangkan stopwords removal adalah mengeluarkan atau membuang kata-kata yang tidak mempunyai makna yang berarti seperti kata depan dan kata penghubung. Beberapa contoh stopwords dalam Bahasa Indonesia yaitu di, ke, dari, dengan, kepada, terhadap, pada, dan yang semisalnya.

c. Menganalisis data (summarized text)

Pada tahapan analisis data, dilakukan perhitungan frekuensi dari kata dalam naskah atau dokumen. Frekuensi kata yang dianalisis dapat berupa unigram (satu kata), bigram (dua kata), dan ngram (lebih dari dua kata).

d. Visualisasi data

Tahapan terakhir dari hasil analisis data adalah visualisasi data. Terdapat beberapa bentuk visualisasi data teksi, di antaranya wordcloud, diagram batang, dan network analysis atau network diagram yang menampilkan pola hubungan dan keterkaitan antar kata.

Analisis data penelitian dengan text mining pada penelitian ini menggunakan bantuan program R. Program R merupakan bahasa pemrograman yang digunakan untuk tujuan komputasi statistik dan analisis data yang dikembangkan oleh Ross Ihaka dan Robet Gentleman pada tahun 1996 (Torgo, 2011).

\section{HASIL DAN PEMBAHASAN}

Text mining telah menjadi sebuah solusi yang sangat baik bagi pengolahan data teks menjadi informasi dan pengetahuan yang berharga. Pengolahan data teks, baik berupa naskah maupun dokumen dapat dilakukan dengan cepat sehingga menghasilkan informasi dan pengetahuan bagi institusi, organisasi, dan masyarakat.

Text mining adalah cara yang digunakan dalam mengolah data penelitian ini, di mana analisis terbagi dalam dua bagian, yaitu analisis saran-saran peserta kegiatan webinar infografis terkait hal-hal yang perlu ditingkatkan dalam pelaksaan kegiatan webinar dan analisis saransaran peserta mengenai topik-topik atau tema 
Hari Linda Luktowati dan Luksi Paryatno, Cendekia Niaga 2021, Volume 5 Nomor 1: hal. 60-68

webinar lanjutan yang dibutuhkan oleh peserta.

Tabel 1 menampilkan 8 saran teratas dari total 115 saran yang diberikan oleh peserta webinar.

Tabel 1. Saran pelaksaan webinar

\begin{tabular}{|l|l|}
\hline No & Saran \\
\hline 1 & $\begin{array}{l}\text { Mohon diselenggarakan pelatihan } \\
\text { lanjutan bagi yang pemula dengan } \\
\text { latihan yang lebih banyak }\end{array}$ \\
\hline 2 & $\begin{array}{l}\text { sarprasnya lebih di tingkatkan supaya } \\
\text { kualitasnya lebih baik }\end{array}$ \\
\hline 3 & untuk masuk dikudagang agak sulit \\
\hline 4 & $\begin{array}{l}\text { Microphone peserta harap dimatikan } \\
\text { saja karena sangat mengganggu, } \\
\text { terkadang suara narasumber malah } \\
\text { tidak terdengar. }\end{array}$ \\
\hline 5 & $\begin{array}{l}\text { peran host dalam mute audio yang } \\
\text { tidak diizinkan }\end{array}$ \\
\hline 6 & $\begin{array}{l}\text { mohon dapat dibuat diklat lebih detail } \\
\text { terkait infografis, misalnya seminggu }\end{array}$ \\
\hline 7 & $\begin{array}{l}\text { Sudah cukup baik. Materi mungkin bisa } \\
\text { diberikan seluma } \\
\text { memungkinkan sehingga pada waktu } \\
\text { penyelenggaraan peserta } \\
\text { kepada paparan narasumber. }\end{array}$ \\
\hline 8 & $\begin{array}{l}\text { Penjelasan Tatib dari Moderator lebih } \\
\text { detail }\end{array}$ \\
\hline
\end{tabular}

Proses cleaning data dilakukan terhadap saran-saran tersebut untuk menghilangkan kata-kata yang tidak memiliki makna, seperti kata hubung dan kata depan. Hasil analisis data setelah melalui proses cleaning ditampilkan pada Gambar 2.

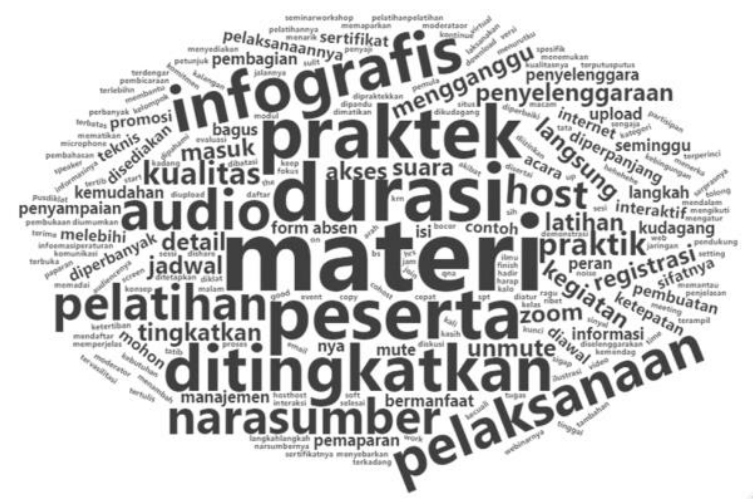

Gambar 2. Wordcloud saran webinar infografis
Gambar 2 merupakan wordcloud saran webinar infografis yang menggambarkan kata yang muncul dalam saran. Wordcloud merupakan bentuk visualisasi yang biasa digunakan untuk data berupa teks atau katakata. Berdasarkan wordcloud di atas, dapat dilihat bahwa kata infografis, praktek, materi, narasumber, dan audio memiliki ukuran yang lebih besar yang berarti kata-kata tersebut memiliki frekuensi muncul yang lebih banyak dibandingkan dengan kata-kata yang lain.

Untuk memperjelas distribusi frekuensi kemunculan kata dalam saran-saran webinar infografis ditunjukkan pada Gambar 3.

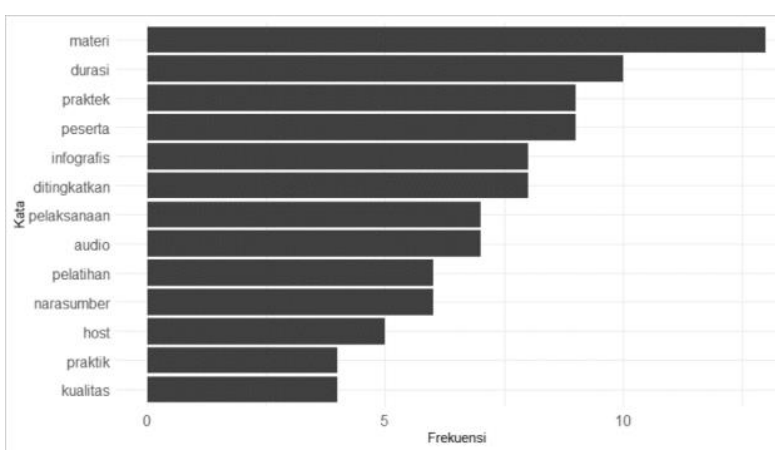

\section{Gambar 3. Frekuensi kata saran webinar infografis}

Berdasarkan gambar di atas, dapat dilihat bahwa kata materi, durasi, praktik, peserta, dan infografis adalah lima kata yang mempunyai frekuensi terbesar. Hal tersebut menunjukkan bahwa peserta webinar infografis menyarankan Pusdiklat Perdagangan lebih memerhatikan dan meningkatkan materi, durasi, dan praktik dalam kegiatan webinar.

Untuk mendapatkan makna yang lebih baik terkait saran-saran peserta webinar maka dilakukan analisis bigram, atau analisis distribusi frekuensi untuk dua kata. Bigram saran-saran webinar infografis ditampilkan pada Gambar 4. 


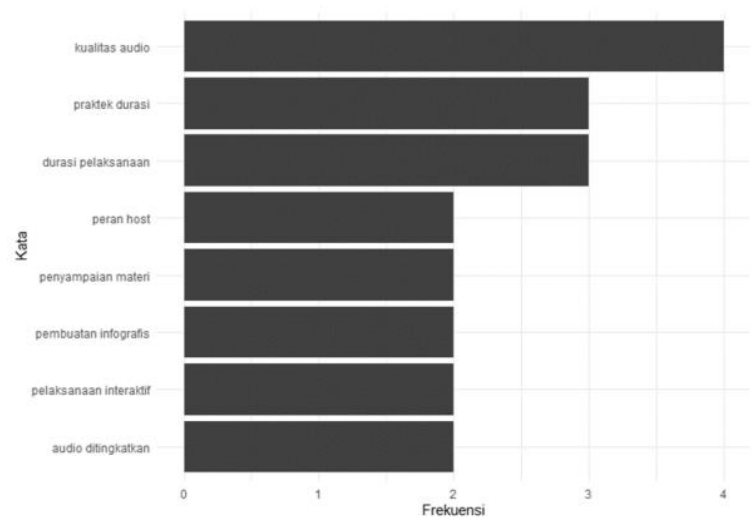

Gambar 4. Frekuensi bigram saran webinar infografis

Frekuensi bigram yang paling besar adalah kualitas audio, artinya hal yang perlu diperhatikan dan diperbaiki dalam penyelengaran kegiatan webinar Pusdiklat Perdagangan adalah kualitas audio selama berjalannya kegiatan webinar. Hal lain yang perlu diperhatikan adalah praktik durasi atau durasi pelaksanaan, artinya dalam menjalankan kegiatan webinar haruslah memerhatikan durasi pelaksanaan yang mencakup ketepatan waktu pelaksanaan dan tersedianya cukup waktu atau durasi bagi peserta untuk melakukan praktik atas materimateri yang disampaikan oleh narasumber. Komposisi yang disarankan untuk durasi pelaksanaan teori dan praktik yaitu $30 \%$ penyampaian teori dan $70 \%$ praktik.

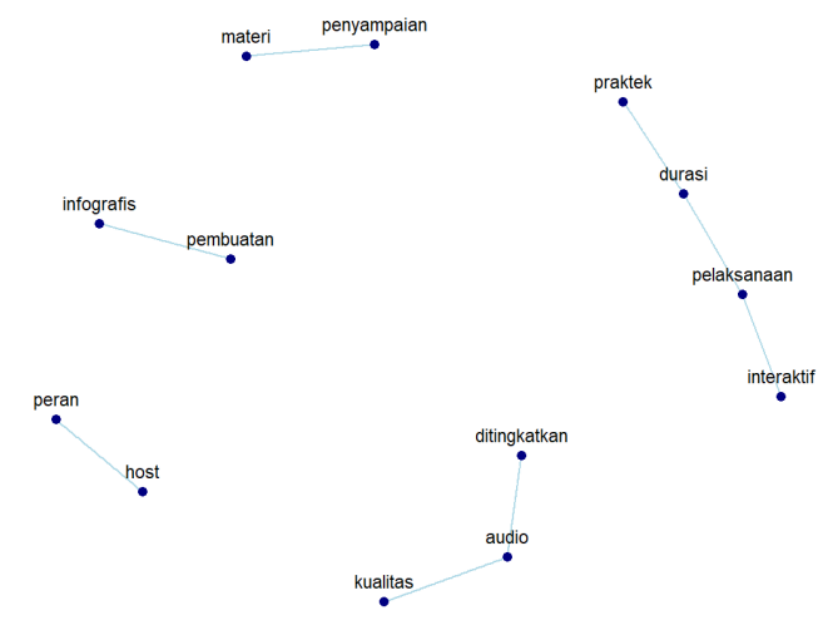

\section{Gambar 5. Network analysis saran webinar infografis}

Gambar 5 merupakan network analysis yang menampilkan hubungan dan asosiasi kata-kata yang ada dalam saran webinar infografis. Berdasarkan gambar tersebut, ditunjukkan bahwa peran host dan penyampaian materi yang dilakukan oleh narasumber juga menjadi hal penting bagi para peserta karena kedua hal tersebut termasuk ke dalam grafik network analysis. Selain itu, pelaksanaan kegiatan webinar khususnya pada sesi praktik disarankan untuk bisa lebih interaktif dengan peserta. Kualitas audio selama berjalannya kegiatan juga harus menjadi perhatian mengingat kegiatan dilakukan secara daring.

Analisis lanjutan dilakukan terhadap saransaran topik webinar yang akan datang. Saran topik webinar ini menjadi catatan penting bagi Pusdiklat Perdagangan untuk memfasilitasi berbagai kebutuhan peserta dan masyarakat pada umumnya. Melalui saran topik, Pusdiklat Perdagangan juga dapat memberikan layanan yang sesuai dan tepat saran.

Tabel 2 menampilkan saran dari 6 peserta teratas webinar infografis yang diberikan kepada Pusdiklat Perdagangan.

\section{Tabel 2. Saran topik webinar}

\begin{tabular}{|l|l|}
\hline No & Saran \\
\hline 1 & $\begin{array}{l}\text { perlu materi yang sesuai dengan } \\
\text { masing masing pekerjaan }\end{array}$ \\
\hline 2 & software infogrfis \\
\hline 3 & tidak ada komentar \\
\hline 4 & $\begin{array}{l}\text { workshop membuat infografis dengan } \\
\text { durasi lebih lama dan lebih banyak } \\
\text { praktik, dengan tools yang relatif } \\
\text { mudah diperoleh dan digunakan }\end{array}$ \\
\hline 5 & Webinar terkait Teknologi dan Informasi \\
\hline 6 & Perdagangan Internasional \\
\hline
\end{tabular}

Kata-kata pada saran topik yang diberikan oleh peserta divisualisasikan dalam bentuk wordcloud yang disajikan pada Gambar 6. 


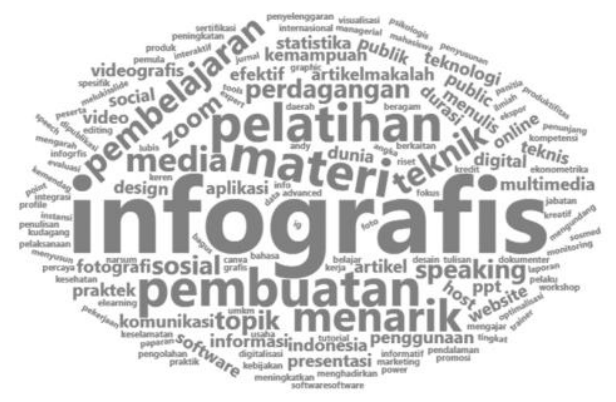

\section{Gambar 6. Wordcloud saran topik webinar}

Dari wordcoud di atas, dapati dilihat kata-kata yang muncul dalam saran topik webinar, di antaranya infografis, pelatihan, materi, menarik, pembelajaran, dan yang lainnya.

Frekuensi kata dari saran-saran topik webinar disajikan dalam Gambar 7.

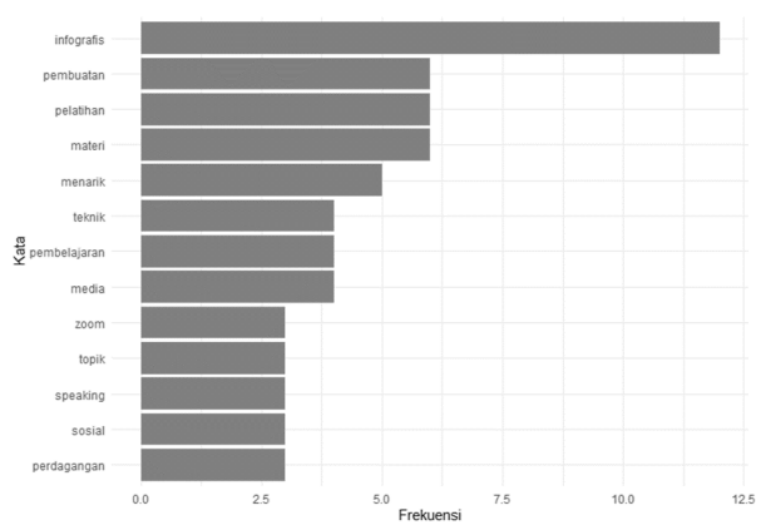

Gambar 7. Frekuensi kata saran topik webinar

Infografis menjadi kata dengan frekuensi muncul paling banyak, kemudian ada kata pembuatan, pelatihan, dan materi. Untuk mendapatkan informasi yang utuh dan bermakna maka analisis saran topik webinar dilakukan melalui bigram dan hasilnya disajikan dalam bentuk wordcloud pada Gambar 8.

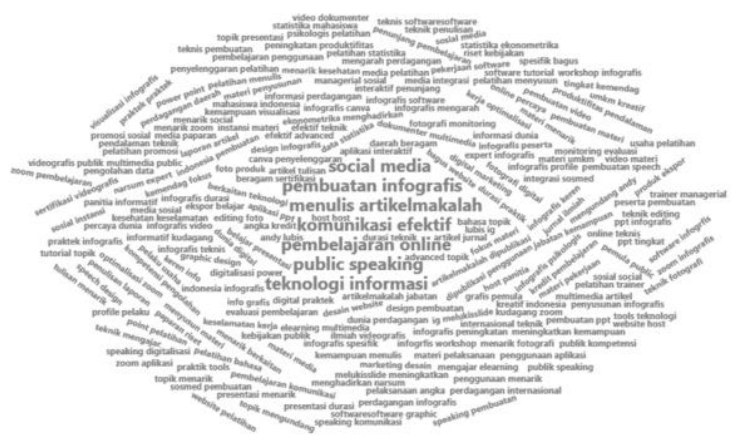

\section{Gambar 8. Wordcloud bigram saran topik webinar}

Bagian tengah wordcloud pada Gambar 8 menampilkan bigram dengan frekuensi terbanyak, yaitu social media, pembuatan infografis, komunikasi efektif, public speaking, dan teknologi informasi. Hal-hal tersebut yang disarankan oleh peserta untuk menjadi topik kegiatan webinar yang akan datang. Saransaran penting tersebut dapat dengan jelas dilihat melalui network analysis yang disajikan pada Gambar 9.

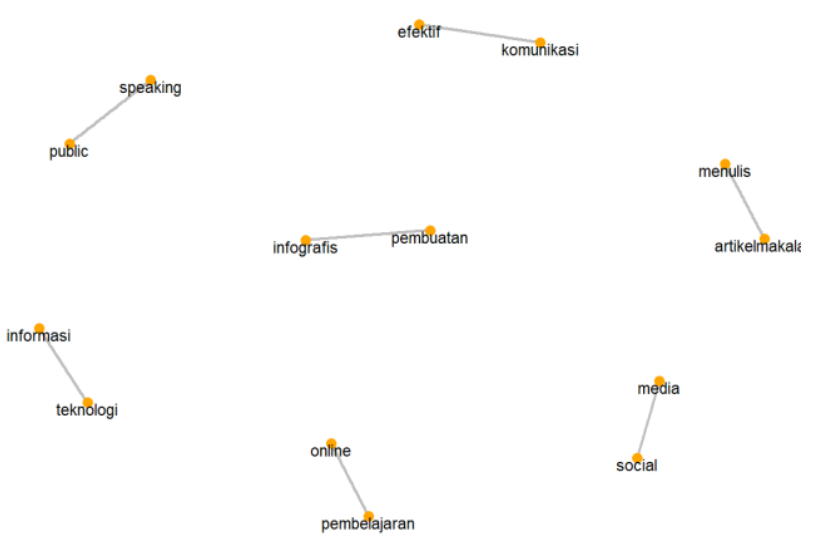

\section{Gambar 9. Network analsysis saran topik webinar}

Hubungan dua kata dapat dilihat lebih jelas melalui network analysis. Berdasarkan Gambar 9, saran topik yang paling banyak diajukan oleh peserta webinar antara lain lanjutan webinar pembuatan infografis. Artinya peserta webinar menginginkan tindak lanjut dari materi infografis yang telah diselenggarakan sebelumnya, mengingat waktu praktik yang tersedia sangat sedikit sebagaimana durasi 
atau waktu praktik juga menjadi saran peserta yang telah disajikan pada Gambar 5.

Topik lain yang diharapkan peserta dapat diselenggarakan adalah terkait komunikasi, meliputi public speaking dan bagaimana komunikasi yang efektif. Selain kedua topik infografis dan komunikasi, peserta juga mengusulkan topik-topik terkait penulisan artikel dan makalah ilmiah, teknologi informasi dan pengelolaan media sosial.

Hasil analisis yang diperoleh, baik saran dalam proses pelaksanaan kegiatan webinar dan topik webinar sangat bermanfaat bagi Pusdiklat Perdagangan untuk dapat merealisasikan harapan dan kebutuhan peserta dan masyarakat pada umumnya.

\section{KESIMPULAN}

Penelitian ini memberikan kontribusi dalam menganalisis data teks yang disampaikan melalui feedback evaluasi kegiatan dengan menggunakan metode text mining. Hasil analisis data pada penelitian ini memberikan beberapa kesimpulan yang dapat menjadi bahan evaluasi dalam perbaikan dan pengembangan kegiatan webinar Pusdiklat Kementerian Perdagangan di waktu mendatang. Evaluasi untuk penyelenggaraan webinar yaitu harus memperhatikan kualitas audio dari narasumber kegiatan dengan memastikan stabilitas jaringan internet dan penggunaan microphone, durasi pelaksanaan kegiatan harus dirancang dengan matang; mencakup rundown kegiatan, ketepatan waktu pelaksanaan, hingga penyesuaian kecukupan waktu untuk sesi praktik. Hal lain yang perlu diperhatikan adalah peran host atau moderator yang proaktif, antara lain memandu jalannya kegiatan agar dapat berjalan dengan baik dan interaktif, serta cepat tanggap terhadap hal-hal yang dapat mengganggu kelancaran kegiatan seperti mematikan audio peserta yang aktif saat narasumber sedang menyampaikan materi.

Evaluasi untuk saran topik webinar yang akan datang di antaranya public speaking dan komunikasi efektif, pembuatan infografis lanjutan, penulisan artikel dan makalah ilmiah, penggunaan teknologi informasi dalam penggunaan media sosial, serta pembelajaran online yang efektif. Berdasarkan kesimpulan ini, Pusdiklat Kementerian Perdagangan diharapkan dapat menyelenggarakan kegiatan webinar dengan topik-topik yang sesuai dengan kebutuhan masyarakat dan memberikan kualitas layanan yang lebih baik.

\section{SARAN}

Saran yang dapat diberikan kepada Pusdiklat Perdagangan antara lain memastikan topik dan materi kegiatan webinar yang akan datang sesuai dengan kebutuhan masyarakat serta memerhatikan aspek-aspek yang menunjang jalannya kegiatan webinar seperti koneksi jaringan internet, kualitas audio, dan peran host dalam kegiatan. Ada pun penelitian lanjutan perlu dilakukan analisis sentimen terhadap feedback yang diberikan oleh peserta.

\section{REFERENSI}

Gegenfurtner, A., \& Ebner, C. (2019). Webinars in Higher Education and Professional Training: A Meta-Analysis and Systematic Review of Randomized Controlled Trials Educational Research Review Webinars in higher education and professional training: A meta- analysis and systematic review of r. Educational Research Review, November. https://doi.org/10.1016/j.edurev.2019.100293

Gegenfurtner, A., Zitt, A., \& Ebner, C. (2019). Evaluating webinar-based training: a mixed methods study of trainee reactions toward digital web conferencing. International Journal of Training and Development, 5-21. https://doi.org/10.1111/ijtd.12167

Heryanto, A., \& Pramudita, R. (2020). Opini Media Sosial Facebook Terhadap Produk Hijab Menggunakan Metode Text Mining. Information System for Educators and Professionals, 4(2), 168-177.

Ismaeel, D. A., Nasser, E., \& Mulhim, A. (2021). The influence of interactive and static infographics on the academic achievement of reflective and impulsive students. Australasian Journal of Educational Technoloy, 37(1), 147-162.

Kumar, L., \& Bhatia, P. K. (2013). Text Mining: Concepts, Process and Applications. Journal of Global Research in Computer Science, 4(3), 3639.

Kwartler, T. (2017). Text Mining in Practice with R. John Wiley \& Sons Ltd.

Mansur, H., \& Rafiudin. (2020). Pengembangan Media Pembelajaran Infografis untuk Meningkatkan Minat Belajar Mahasiswa. Jurnal 
Hari Linda Luktowati dan Luksi Paryatno, Cendekia Niaga 2021, Volume 5 Nomor 1: hal. 60-68 Komunikasi Pendidikan, 4(1), 37-48.

Novialdy, Darussalam, U., \& Rahman, B. (2020). Expert System of Text Mining to Analyze Student Interaction in FTKI UNAS Online Lectures. 3(4), 268-277.

Olive, I., Putra, D., Prilianti, K. R., Lucky, P., \& Irawan, T. (2020). Implementasi Text Mining untuk Analisis Layanan Transportasi Online dengan Analisis Faktor. Jurnal SimanteC, 8(2).

Rachman, N. M. (2020). Journal of Trade Development and Studies EVALUASI PENYELENGGARAAN WEBINAR: STRATEGI UMKM KOREA SELATAN BERTAHAN DALAM PANDEMI COVID-19 Abstrak. Cendekia Niaga:Journal of Trade Development and Studies, 2(2), 1-15.

Silge, J., \& Robinson, D. (2017). Text Mining with R A Tidy Approach (1st ed.). O'Reilly.

Sipayung, A. D., Fauziah, \& Nurhayati. (2020). Sistem Aplikasi Penilaian Jawaban Essay Test Calon Karyawan PT Siloam Hospitals TB Simatupang Menggunakan Algoritma Text Mining TF-IDF Berbasis Web. Jurnal Media Informatika Budidarma, $\quad 4(2012), \quad 872-878$. https://doi.org/10.30865/mib.v4i4.2202

Torgo, L. (2011). Data Mining with R: Learning with Case Studies. Taylor and Francis Group. 